Pesq. Vet. Bras. 29(7):583-588, julho 2009

\title{
Intoxicação por Ipomoea carnea subsp. fistulosa (Convolvulaceae) em caprinos na llha do Marajó, Pará1
}

\author{
Carlos Alberto Oliveira², José Diomedes Barbosa², Marcos Dutra Duarte ${ }^{2}$, \\ Valíria Duarte Cerqueira², Franklin Riet-Correa ${ }^{3}$, Fábio Py Tortelli ${ }^{4}$ \\ e Gabriela Riet-Correa ${ }^{2 *}$
}

\begin{abstract}
Oliveira C.A., Barbosa J.D., Duarte M.D., Cerqueira V.D., Riet-Correa F. \& Riet-Correa G. 2009. [Poisoning by Ipomoea carnea subsp. fistulosa in goats in the Marajó island, Pará.] Intoxicação por Ipomoea carnea subsp. fistulosa (Convolvulaceae) em caprinos na llha do Marajó, Pará. Pesquisa Veterinária Brasileira 29(7):583588. Central de Diagnóstico Veterinário, Campus de Castanhal, Universidade Federal do Pará, Rua Maximino Porpino da Silva 1000, Pirapora, Castanhal, PA 68743-080, Brazil. E-mail: griet@ufpa.br

Ipomoea carnea subsp. fistulosa is a swainsonine-containing plant causing a glycoprotein storage diseases in ruminants, mainly in goats in northeastern Brazil. Seven farms were visited on the Marajo Island, state of Pará, northern Brazil, six in the municipality of Cachoeira do Arari and one in the municipality of Soure. In all farms native pastures had shortage of forage and were largely invaded by I. carnea subsp. fistulosa. On the three farms goats presented difficulties in standing, ataxia, hypermetria, wide-based stance, lateral gait, intention tremors, spastic paresis or weakness, abnormal postural reactions, nystagmus, loss of equilibrium and falling to the side or backward. On two farms the prevalence was of $32 \%$ (23/71) and 100\% (32/32). On another farm one goat out of 19 had severe clinical signs, but the others of the flock were not examined clinically. Cattle, sheep and buffaloes were not affected. Six goats were euthanized and necropsied. No gross lesions were observed. Upon histological examination the main lesion was the vacuolization of the perikaryon of neurons and cytoplasm of epithelial cells of thyroid, liver, kidney, pancreas and macrophages of different organs. In the central nervous system the vacuolization of the perikaria was more severe in Purkinje cells of the cerebellum and in nuclei of the brain stem, mainly the cerebellar nuclei. Wallerian degeneration of axons and gliosis was also observed. The high frequency of the disease on the three farms suggests that poisoning by I. carnea subsp. fistulosa is very important for goats on Marajó Island where there are large amounts of the plant in the pastures.
\end{abstract}

INDEX TERMS: Poisonous plants, Ipomoea carnea, plant poisoning, goats, swaisonine, diseases of nervous system.

\footnotetext{
${ }^{1}$ Recebido para publicação em 2 de março de 2009.

Aceito para publicação em 24 de março de 2009.

2 Central de Diagnóstico Veterinário, Campus de Castanhal, Universidade Federal do Pará, Rua Maximino Porpino da Silva 1000, Pirapora, Castanhal, PA 68743-080, Brasil. *Autor para correspondência: griet@ufpa.br

${ }^{3}$ Hospital Veterinário, Centro de Saúde e Tecnologia Rural (CSTR), Universidade Federal de Campina Grande (UFCG), Campus de Patos, 58700-970 Patos, PB, Brasil.

${ }^{4}$ Programa de Pós-Graduação em Ciência Animal, Núcleo de Ciências Agrárias e Desenvolvimento Rural, Rua Augusto Corrêa 1, Campus Universitário do Guamá, Belém, PA 66075-110, Brasil.
}

RESUMO.- Ipomoea carnea subsp. fistulosa é uma planta que contém swainsonina causando doença de depósito lisossomal em ruminantes, principalmente em caprinos na região Nordeste do Brasil. Para o estudo das plantas tóxicas da llha de Marajó, foram visitadas sete propriedades rurais na llha de Marajó, seis localizadas no município de Cachoeira do Arari e uma no município de Soure. Em todas as propriedades visitadas as pastagens eram constituídas de campo nativo, tinham pouca disponibilidade de forragem e I. carnea subsp. fistulosa encontrava-se em grande quantidade. Nas três propriedades onde eram criados 
caprinos foram observados animais com sinais nervosos, incluindo tremores de intenção, aumento da base de sustentação quando em estação, ataxia, hipermetria, nistagmo, paresia espástica ou debilidade, alterações posturais, perda de equilíbrio e quedas. Em duas fazendas a prevalência foi de $32 \%$ (23/71) e 100\% (32/32) e em outra havia um animal com sinais acentuados e o resto do rebanho, de 19 caprinos, não foi examinado clinicamente. Bovinos, ovinos e bubalinos não foram afetados. Foram eutanasiados e necropsiados seis caprinos que apresentavam sinais clínicos acentuados. Macroscopicamente não foram observadas alterações. Na histologia observou-se vacuolização do pericário de neurônios e do citoplasma de células epiteliais da tireóide, rim, fígado, pâncreas e macrófagos de diversos órgãos. No sistema nervoso central a vacuolização era mais grave nos neurônios de Purkinje do cerebelo e nos neurônios dos núcleos cerebelares e do tronco encefálico. Observaram-se também degeneração walleriana dos axônios e gliose. A alta freqüência da intoxicação nas três fazendas que criavam caprinos sugere que a intoxicação por I. carnea subsp. fistulosa é muito importante para caprinos na llha de Marajó, onde há abundante quantidade da planta, que permanece verde durante todo o período seco.

TERMOS DE INDEXAÇÃO: Plantas tóxicas, Ipomoea carnea, caprinos, intoxicação por planta, swaisoninas, doenças do sistema nervoso.

\section{INTRODUÇÃO}

Ipomoea carnea subsp. fistulosa, (Convolvulaceae), conhecida como algodão bravo, canudo, manjorana, capa-bode ou mata-cabra, é uma planta que causa doença de depósito lisossomal em ruminantes, principalmente em caprinos (Tokarnia et al. 1960, Armien et al. 2007, Guedes et al. 2007), mas tem sido observada também em bovinos (Tokarnia et al. 1960, Antoniassi et al. 2007) e ovinos (Tokarnia et al. 1960).

O principio ativo de $I$. carnea subsp. fistulosa é o alcalóide indolizidínico swainsonina, que inibe a atividade das enzimas $\alpha$-manosidase lisossomal e $\alpha$-manosidase II do aparelho de Golgi. Em amostras de I. carnea subsp. fistulosa têm sido identificadas, também, calisteginas $B_{1}$, $B_{2}, B_{3}$ e $C_{1}$ (Haraguchi et al. 2003).

A intoxicação por I. carnea subsp. fistulosa ocorre freqüentemente em caprinos na região Nordeste, principalmente no Vale do Rio São Francisco (Tokarnia et al. 2000, Armien et al. 2007, Guedes et al. 2007). Nessa região é uma das poucas plantas que se conserva verde durante 0 período de seca, sendo considerada planta tóxica importante e bem conhecida (Tokarnia et al. 2007). No Mato Grosso, I. carnea subsp. fistulosa ocorre comumente no Pantanal Mato-grossense, e casos de intoxicação em bovinos têm sido descritos (Antoniassi et al. 2007). No Estado do Rio de Janeiro I. carnea subsp. fistulosa é utilizada freqüentemente para formação de cercas vivas (Tokarnia et al. 2000) e raramente causa intoxicação (Tokarnia et al. 2007).

$\mathrm{Na}$ llha de Marajó observa-se grande quantidade de $I$. asarifolia e I. carnea subsp. fistulosa nas pastagens. Nessa região já foi descrita a intoxicação por $I$. asarifolia em bovinos (Barbosa et al. 2005, Tortelli et al. 2008) e ovinos (Tortelli et al. 2008), mas não há relatos da intoxicação por essas plantas em caprinos. O objetivo do presente trabalho foi descrever a intoxicação por l. carnea subsp. fistulosa em caprinos na llha de Marajó.

\section{MATERIAL E MÉTODOS}

Foram visitadas, durante o período seco, sete propriedades rurais na Ilha de Marajó, seis localizadas no município de Cachoeira do Arari e uma no município de Soure,. Em uma das propriedades localizadas no município de Cachoeira do Arari foram realizadas duas visitas, uma no período seco e outra no período chuvoso. Durante as visitas foram realizados levantamento das plantas tóxicas existentes, estudo epidemiológico da doença, avaliação clínica de animais afetados, necropsias de animais gravemente doentes e coleta de material para estudo histopatológico. Foram eutanasiados e necropsiados seis caprinos, sendo coletados fragmentos de todos os órgãos da cavidade abdominal e torácica, tireóide, encéfalo e medula cervical, torácica e lombar e fixados em formalina neutra a 10\%. O encéfalo, após a fixação, foi cortado transversalmente, coletando-se fragmentos nas regiões do córtex parietal, temporal, occipital e frontal, núcleos da base, tálamo, mesencéfalo a altura do colículo rostral, pedúnculos cerebelares, cerebelo, ponte e óbex. Após a fixação as amostras foram incluídas em parafina, cortadas a $6 \mu \mathrm{m}$ e coradas com Hematoxilina-Eosina (HE).

\section{RESULTADOS}

Todas as propriedades visitadas eram constituídas de campo nativo, e tinham pouca disponibilidade de forragem durante o período seco. Ipomoea carnea subsp. fistulosa foi observada em todos os campos em grande quantidade, estava sempre verde e continha flores e frutos. Havia, também, Ipomoea asarifolia em grande quantidade. Em três das sete propriedades visitadas eram criados caprinos. Nessas três propriedades foram observados animais com sinais nervosos caracterizados por tremores de intenção, ataxia, hipermetria, nistagmo, aumento da base de sustentação, dificuldade de locomoção com espasticidade ou debilidade, principalmente dos membros posteriores, e marcha de lado, perda de equilíbrio e quedas para trás ou de lado. Os proprietários relataram que a doença ocorria principalmente no período seco, mas casos podiam ser observados durante todo o ano, visto que os caprinos continuavam a ingerir algodão bravo mesmo quando havia disponibilidade de forragem.

Em uma propriedade, localizada no município de Soure, formada por 1900 ha, divididos em três unidades de produção (retiros), eram criados caprinos em dois desses. Em todos os retiros havia grande quantidade de $I$. carnea subsp. fistulosa (Fig.1). Em um dos retiros eram criados bubalinos e 32 caprinos. Os caprinos estavam há três anos nesse retiro e casos da intoxicação nunca tinham sido observados. No outro retiro havia bubalinos e 71 caprinos. Segundo o tratador, no ano de 2006 a seca foi prolongada e as chuvas começaram no final de janeiro. Nesse ano vários caprinos apresentaram sinais ner- 

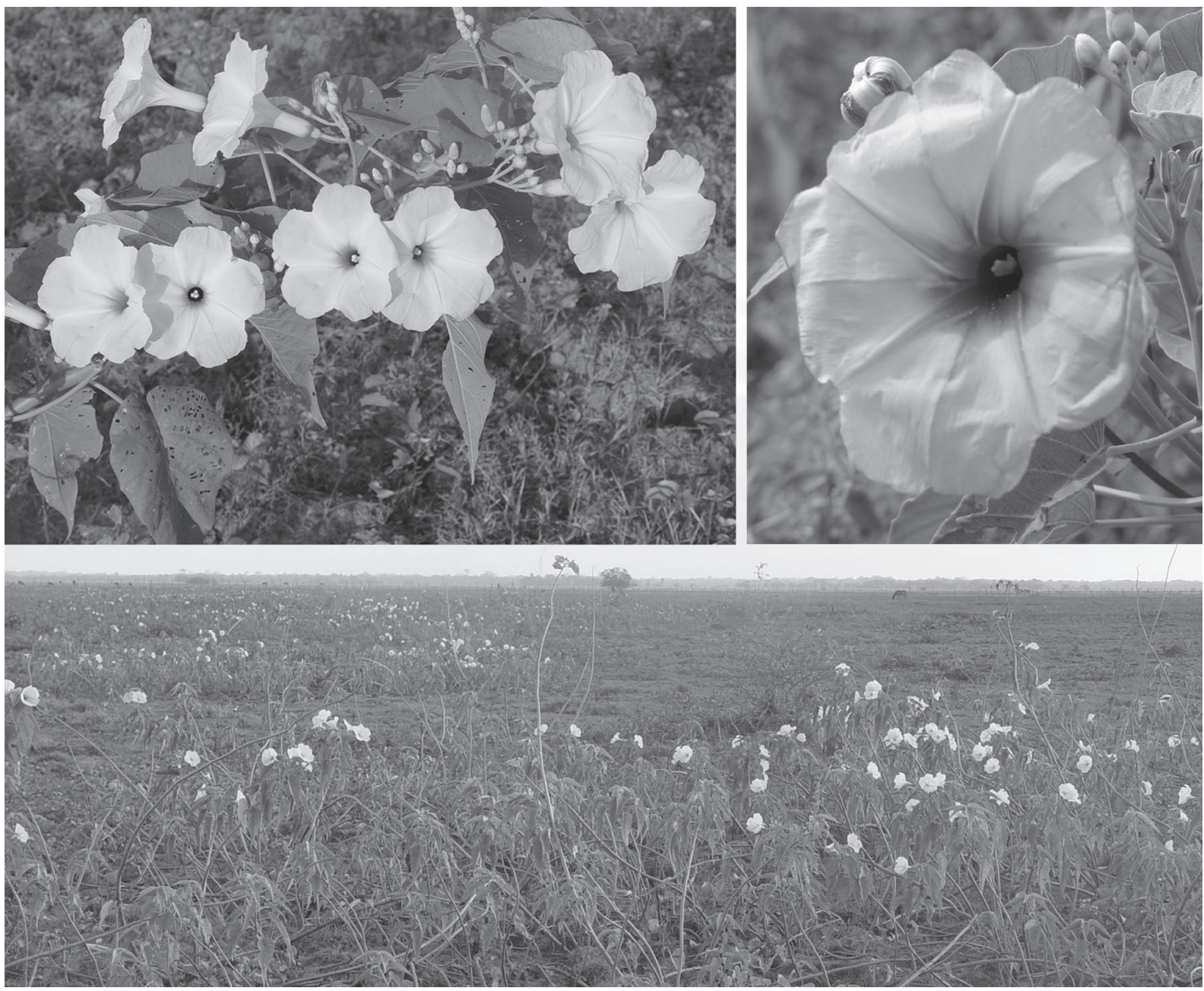

Fig.1. Pasto severamente invadido por Ipomoea carnea subp fistulosa. Município de Soure, Ilha do Marajó, PA.

vosos e oito morreram com sinas clínicos acentuados. Em anos anteriores a doença não havia sido observada. No momento da visita, dos 71 caprinos, quatro apresentavam sinais clínicos acentuados caracterizados por aumento da base de sustentação quando em estação, hipermetria e quedas em decúbito lateral ao serem movimentados, permanecendo deitados com opistótono e espasticidade dos membros por alguns segundos (Fig.2). Dezenove animais apresentavam tremores da cabeça de graus leve a moderado, sendo que alguns destes apresentavam, ainda, discreta hipermetria ao serem movimentados. Foi observado que, a pesar de haver pouca pastagem disponível para alimentação dos animais, os caprinos estavam em boas condições corporais. Segundo o tratador, na época seca eles ingeriam grande quantidade dos frutos de uma árvore conhecida como Siriubeira. Os quatro animais que apresentavam sinais clínicos acentuados foram eutanasiados e necropsiados.

Em outra propriedade, localizada no município de Cachoeira do Arari, eram criados aproximadamente 32 caprinos e todos os animais apresentavam tremores da cabeça. Três animais apresentavam sinais clínicos acentu- ados, como aumento da base de sustentação quando em estação, ataxia, hipermetria e quedas em decúbito lateral ao serem movimentados, permanecendo deitados com opistótono e espasticidade dos membros por alguns segundos. Segundo o proprietário, a doença foi observada pela primeira vez na sua propriedade no ano de 2005. Ele relatou, também, que a doença ocorria em todas as propriedades vizinhas, com aproximadamente $100 \%$ de prevalência em caprinos. Foram eutanasiados e necropsiados dois caprinos que apresentavam sinais clínicos acentuados. Segundo o proprietário, embora no período chuvoso a disponibilidade de pastagem seja melhor, os caprinos continuavam a ingerir a planta.

Em outra propriedade, também localizada no município de Cachoeira do Arari, havia 19 caprinos. Foi observado um caprino com sinais clínicos acentuados semeIhantes aos descritos anteriormente. Não foi possível examinar todos os animais, pois eles estavam soltos pela propriedade. Segundo o proprietário a doença ocorria em outras propriedades vizinhas afetando caprinos. Os casos de intoxicação ocorriam principalmente no período seco, mas podiam ser observados durante todo o ano. 

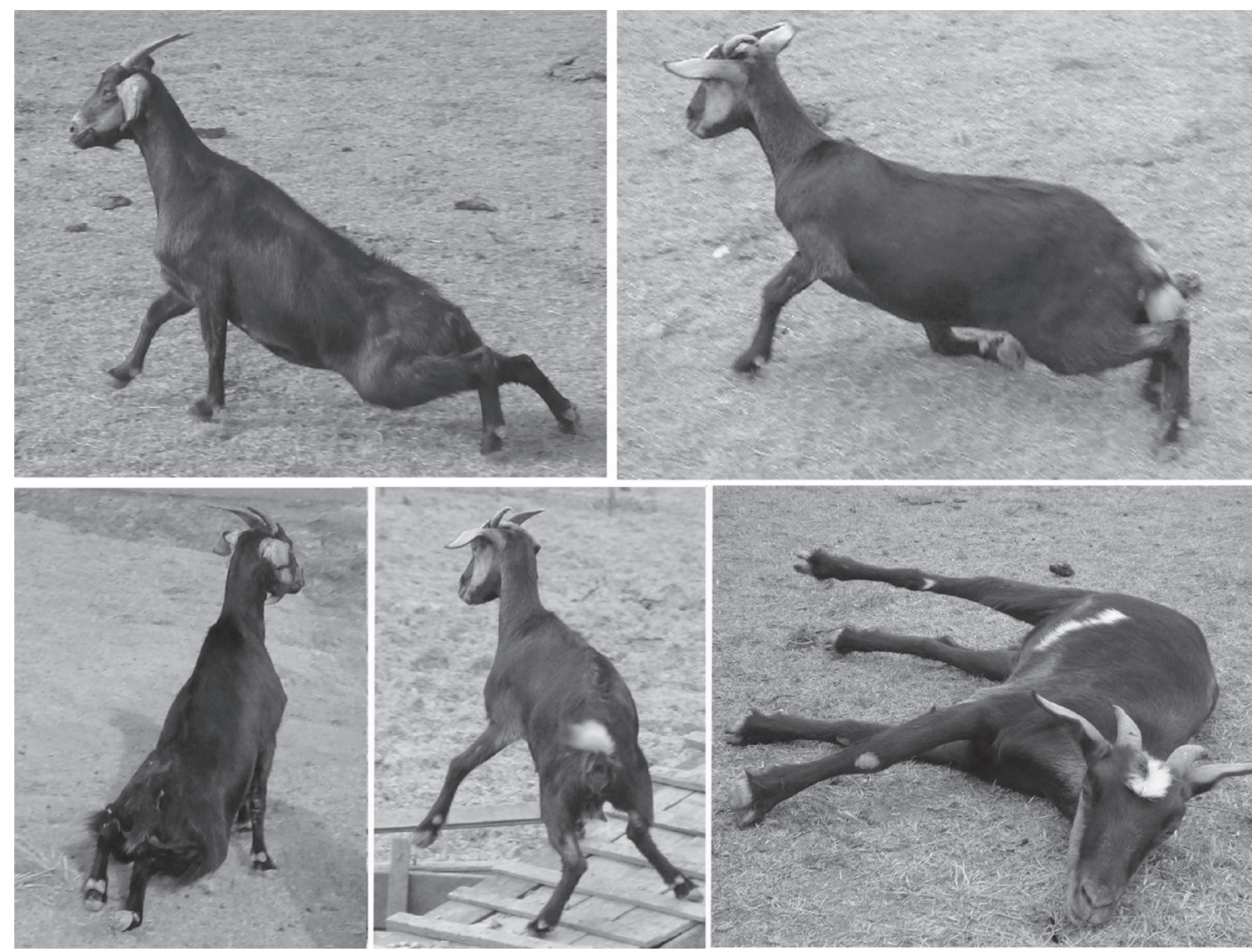

Fig.2. Caprino intoxicado espontaneamente por Ipomoea carnea subp. fistulosa, apresentando incoordenação, debilidade dos membros posteriores, hipermetria e quedas.

Em todas as necropsias realizadas não foram observadas alterações macroscópicas. Histologicamente havia vacuolização acentuada do pericário de neurônios do sistema nervoso central, mais marcada nas células de Purkinje do cerebelo, núcleos cerebelares e outros núcleos do tronco encefálico (Fig.3). Alguns neurônios do cerebelo e dos núcleos cerebelares apresentavam núcleos picnóticos e marginalizados e citoplasma espumoso e pálido sem bordas definidas (Gost cells = células fantasmas) (Fig.3A-C). Em outras regiões havia desaparecimento dos neurônios de Purkinje e proliferação da glia de Bergmann (Fig.3D). Degeneração Walleriana, caracterizada pela presença de numerosos esferóides axonais, elipsóides de mielina, alguns com resíduos de axônios ou macrófagos no seu interior (Fig.4), e gliose eram observados, principalmente na sustância branca cerebelar e pedúnculos cerebelares. Havia, também, vacuolização do citoplasma de células epiteliais da tireóide, rim, fígado, pâncreas (Fig.5) e macrófagos de diversos órgãos.

\section{DISCUSSÃO}

O diagnóstico da intoxicação por Ipomoea carnea subsp. fistulosa nos caprinos deste estudo foi baseado nos dados epidemiológicos, sinais clínicos e achados histopatológicos, caracterizados principalmente por vacuolização de neurônios e de células epiteliais de outros órgãos. Essas alterações histológicas são semelhantes às descritas na intoxicação por I. carnea subsp. fistulosa em caprinos, ovinos e bovinos (Tokarnia et al. 2000, Armien et al. 2007, Guedes et al. 2007) e deve-se ao acúmulo de oligossacarídeos incompletamente processados no interior das células (De Balogh et al. 1999, Haraguchi et al. 2003). Outras plantas que contêm swainsonina (Ipomoea riedelii, Ipomoea sericophylla, Sida carpinifolia e Turbina cordata) e causam lesões semelhantes (Riet-Correa \& Méndez 2007) não se encontravam nas pastagens. A presença de lesões histológicas permitiu diferenciar essa doença da intoxicação por I. asarifolia, que também estava presente em todas as propriedades e que causa sinais clínicos semelhantes aos da intoxicação por I. carnea. Além disso, na ilha de Marajó, I. asarifolia afeta ovinos (Tortelli et al. 2008) e bovinos (Barbosa et al. 2005, Tortelli et al. 2008) os quais apresentam sinais clínicos reversíveis.

Em todas as propriedades onde eram criados caprinos foram observados animais doentes e os proprietários relataram que a doença ocorre principalmente no período seco, mas casos podem ser observados durante todo o ano, visto que os caprinos continuam a ingerir algodão bravo mesmo na época de chuvas. A ocorrência da intoxicação mesmo em épocas de boa disponibilidade de forragem ocorre por que animais intoxicados desenvolvem avidez pela planta, continuando a ingeri-la mesmo quan- 

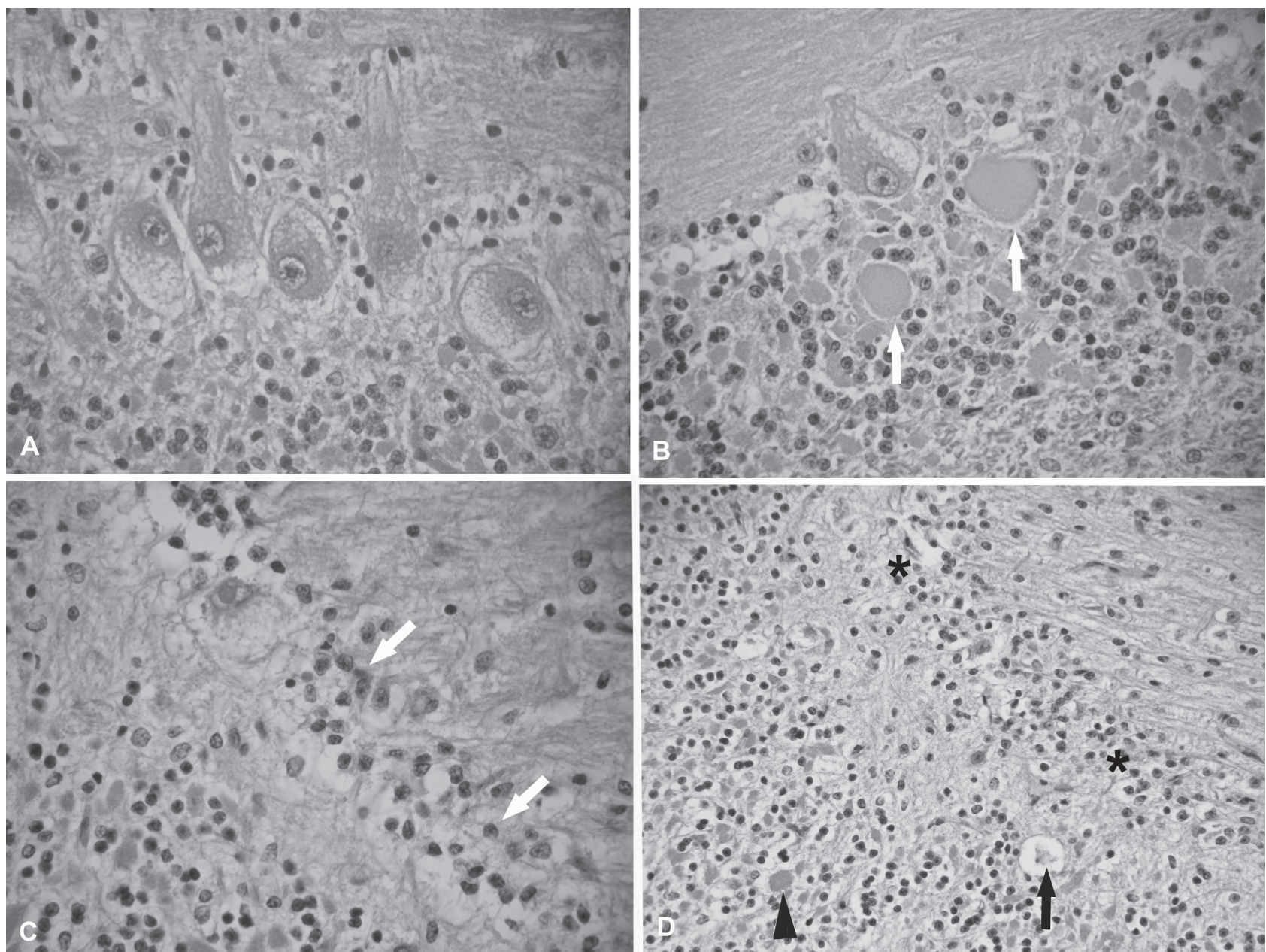

Fig.3. Cerebelo de caprino. Intoxicação por Ipomoea carnea subp. fistulosa. (A) Neurônios de Purkinje com pericário vacuolizado e núcleo excêntrico. (B) Neurônio de Purkinje com pericário vacuolizado e núcleo excêntrico e esferóides axonais na camada granular (setas). (C) Neurônios de Purkinje vacuolizado e necrótico (neurônios fantasma, gost cells) e proliferação da glia de Bergmann (setas). (D) Desaparecimento de neurônios de Purkinje e proliferação da glia de Bergmann (asteriscos). Na camada granular observam-se um esferóide axonal (cabeça de seta), uma cavidade com resíduo axonal e um macrófago (seta). HE, obj.20x.

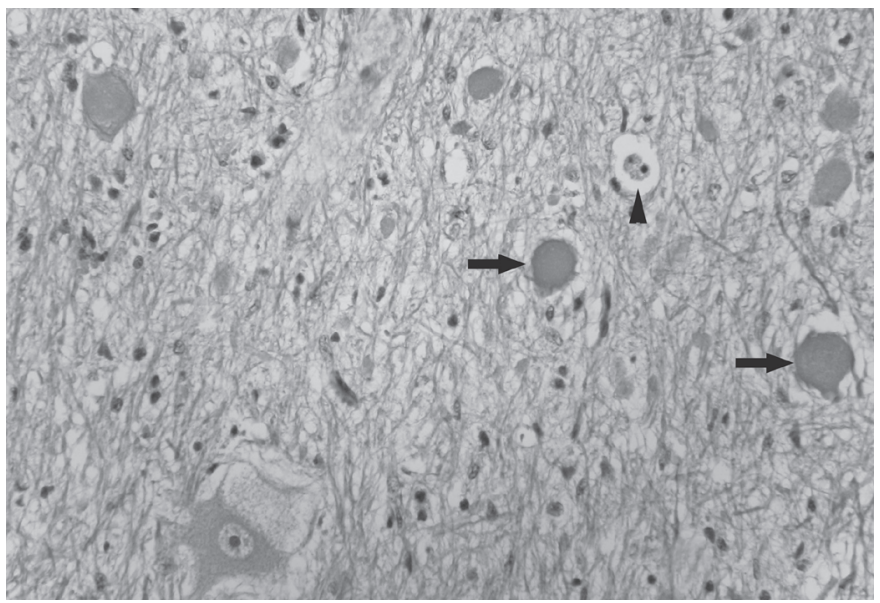

Fig.4. Medula cerebelar de caprino. Intoxicação por Ipomoea carnea subp. fistulosa. Observam-se numerosos esferóides axonais (setas), cavidade contendo macrófagos (cabeça de seta) e neurônio com vacuolização do pericário. HE, obj.20x.

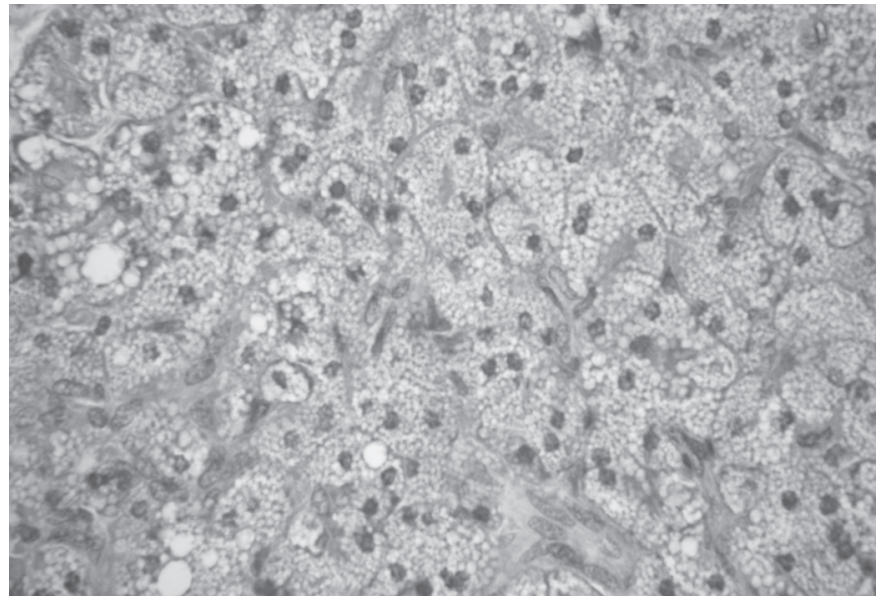

Fig.5. Pâncreas de caprino. Intoxicação por Ipomoea carnea subp. fistulosa. Observa-se vacuolização severo do citoplasma das células epiteliais. HE, obj.20x. 
do há outra alimentação disponível. Além disso, os animais que aprendem a ingerir a planta fazem com que os outros animais a ingiram. Isso trate-se de facilitação social, processo pelo qual animais que não ingerem determinadas plantas aprendem a ingeri-las na presença de outros animais que a ingerem (Riet-Correa \& Méndez 2007). Esses animais que procuram a planta são conhecidos como "canudados", "canudeiros" ou "encanudados" (Tokarnia et al. 1960, 2000).

Chama a atenção que somente em um retiro de uma das fazendas visitadas não havia caprinos doentes, provavelmente por que nesse rebanho não havia animais que ingerissem a planta. Nas outras fazendas o que provavelmente ocorreu é que alguns animais iniciaram a ingerir a planta em algum momento de escassez de forragem e, posteriormente, por facilitação social, outros animais também começaram a ingerir I. carnea subsp. fistulosa. Perante esse comportamento a única alternativa de controlar a intoxicação é evitar que caprinos permaneçam em áreas onde ocorra a planta durante épocas de escassez de forragem. Além disso, caprinos que iniciem a ingerir a planta ou apresentem sinais clínicos devem ser retirados do rebanho. Os animais que deixam de ingerir plantas contendo swainsonina dentro de 30 dias após a observação dos primeiros sinais clínicos podem se recuperar clinicamente (Barbosa et al. 2007). Uma forma de controle da doença poderia ser a indução de aversão condicionada nos animais que ingerem a planta. Em um estudo preliminar, cabras que apresentavam sinais permanentes de intoxicação por Turbina cordata e foram avertidas mediante a administração de cloreto de lítio, permaneceram pelo menos seis meses sem ingerir a planta (Dantas et al. 2008).

Neste trabalho não foram observados casos de intoxicação por I. carnea subsp. fistulosa em bovinos, ovinos e bubalinos, mas não pode ser descartada a ocorrência da doença nessas espécies, como ocorre no Pantanal Matogrossense em bovinos (Antoniassi et al. 2007) e no Vale do São Francisco em bovinos e ovinos (Tokarnia et al. 1960, 2000). É necessário estar atento para a possível ocorrência da intoxicação nessas espécies para, nesse caso, evitar a difusão do hábito de ingerir a planta, mediante a eliminação dos animais ou rebanhos que a ingerem.

Caprinos intoxicados por I. carnea podem apresentar sonolência, emagrecimento progressivo, pêlos arrepiados, e sinais nervosos caracterizados por ataxia, hipermetria, paresia espástica, tremores de intenção, nistagmo, aumento da base de sustentação e posturas anormais. Quando movimentados ou agitados os sinais são exacerbados podendo observar-se marcada incoordenação dos membros posteriores ou quedas (Tokarnia et al. 2000, RietCorrea \& Méndez 2007, Guedes 2007). No presente estudo foram observados sinais nervosos semelhantes aos descritos acima, mas não foi observado sonolência nem emagrecimento progressivo. Todos os caprinos da propriedade localizada no município de Soure estavam em boas condições corporais, provavelmente devido à ingestão de sementes de uma árvore conhecida na re- gião como Siriubeira. Nos quatro animais dessa propriedade que foram necropsiados observou-se grande quantidade dessas sementes no rúmen.

Os resultados deste trabalho mostram que a intoxicação por I. carnea subsp. fistulosa causa perdas econômicas importantes para a caprinocultura das fazendas estudadas. Além disso, a alta freqüência da doença nas três fazendas que criavam caprinos e a ampla distribuição de I. carnea subsp. fistulosa na ilha de Marajó sugerem que a intoxicação por esta planta é de importância para caprinos nesta ilha.

Agradecimentos.- Este projeto foi financiado pelo programa Institutos do Milênio, CNPq (Proc.420012/2005-2).

\section{REFERÊNCIAS}

Antoniassi N.A.B., Ferreira E.V., Santos C.E.P., Campos J.L.E., Nakazato L. \& Colodel E.M. 2007. Intoxicação espontânea por Ipomoea carnea subsp. fistulosa (Convolvulaceae) em bovinos no Pantanal Matogrossense. Pesq. Vet. Bras. 27(10):415-418.

Armién A.G., Tokarnia C.H., Peixoto P.V. \& Frees K. 2007. Spontaneous and experimental glycoprotein storage disease of goats induced by Ipomoea carnea subsp. fistulosa (Convolvulaceae). Vet. Pathol. 44:170-184.

Barbosa J.D., Oliveira C.M.C., Duarte M.D., Peixoto P.V. \& Tokarnia C.H. 2005. Intoxicação experimental e natural por Ipomoea asarifolia (Convolvulaceae) em búfalos e outros ruminantes. Pesq. Vet. Bras. 25:231-234.

Barbosa R.C., Riet-Correa F., Lima E.F., Medeiros R.M.T., Guedes K.M.R., Gardner D.R., Molyneux R.J. \& Melo L.E.H. 2007. Experimental swainsonine poisoning in goats ingesting Ipomoea sericophylla and Ipomoea riedelii (Convolvulaceae). Pesq. Vet. Bras. 27(10): 409-414.

Dantas A.F.M., Riet-Correa F. \& Medeiros R.M.T. 2008. Indução de aversão alimentar condicionada em caprinos intoxicados espontaneamente por Turbina cordata. Anais III Encontro Nacional de Diagnóstico Veterinário, Campo Grande, MS. (CD Room)

De Balogh K.K., Dimande A.P., Van Der Lugt J.J., Molyneux R.J., Naudé T.W. \& Welman W.G. 1999. A lysosomal storage disease induced by Ipomoea carnea in goats in Mozambique. J. Vet. Diag. Invest. 11(3):266-273.

Guedes K.M.R., Riet-Correa F., Dantas A.F.M., Simões S.V.D., Miranda Neto E.G., Nobre V.T.M. \& Medeiros R.M.T. 2007. Doenças do sistema nervoso central de caprinos e ovinos no semi-árido. Pesq. Vet. Bras. 27:25-34

Haraguchi M., Gorniak S.L., Ikeda K., Minami H., Kato A., Watson A.A., Nash R., Molyneux R.J. \& Asano N. 2003. Alkaloidal components in the poisonous plant Ipomoea carnea (Convolvulaceae). J. Agric. Food Chem. 51: 4995-5000.

Riet-Correa F. \& Méndez M.D.C. 2007. Intoxicação por plantas e micotoxinas, p.99-219. In. Riet-Correa F., Schild A.L., Lemos A.A. \& Borges J.R. (Eds), Doenças de Ruminantes e Eqüídeos. Vol. 2. $3^{\underline{a}}$ ed. Pallotti, Santa Maria. 694p.

Tokarnia C.H., Döbereiner J. \& Canella C.F.C. 1960. Estudo experimental sobre a toxidez do "canudo" (Ipomoea fistulosa Mart.) em runinantes. Arqs Biol. Animal, Rio de J., 3:59-71.

Tokarnia C.H., Döbereiner J. \& Peixoto P.V. 2000. Plantas que causam perturbações nervosas, p.120-124. In: Ibid. (Eds), Plantas Tóxicas do Brasil. Editora Helianthus, Rio de Janeiro,

Tortelli P.F., Barbosa J.D., Oliveira C.M.C., Dutra M.D., Cerqueira V.D., Oliveira C.A., Riet-Correa F. \& Riet-Correa G. 2008. Intoxicação por Ipomoea asarifolia em bovinos e ovinos na llha de Marajó. Pesq. Vet. Bras. 28(12):622-626. 